\title{
Loranthaceae endémicas del Perú
}

\section{Blanca León ${ }^{1,2}$}

${ }^{1}$ Museo de Historia Natural, Av. Arenales 1256, Aptdo. 14-0434, Lima 14, Perú

2 Plant Resources Center, University of Texas at Austin, Austin TX 78712 EE.UU.

blanca.leon@mail.utexas.edu

\section{Resumen}

La familia Loranthaceae está representada en la flora peruana por 11 géneros y 63 especies (Brako \& Zarucchi, 1993; Ulloa Ulloa et al., 2004), la mayoría arbustos. En este trabajo se reconoce 14 especies endémicas en cinco géneros. Los endemismos en esta familia ocupan diversas regiones, como la Mesoandina, Puna Húmeda y Seca y Bosques Muy Húmedos Montanos, desde los 1400 hasta los $4200 \mathrm{~m}$ de altitud. Se aplicaron las categorías y criterios de la UICN a 11 especies. Cinco especies endémicas se encuentran representadas en del Sistema Nacional de Áreas Naturales Protegidas por el Estado.

Palabras claves: Loranthaceae, Perú, endemismo, plantas endémicas.

\section{Abstract}

The Loranthaceae are represented in Peru by 11 genera and 63 species (Brako \& Zarucchi, 1993; Ulloa Ulloa et al., 2004), mostly shrubs. Here we recognize 14 endemic species in five genera. These endemics grow in a variety of different regions, including Mesoandean, Humid and Dry Puna, and Humid Montane Forest, between 1400 and 4200 m elevation. We applied IUCN categories and criteria to 11 species. Five of these species have been found within the Peruvian protected areas system.

Keywords: Loranthaceae, Peru, endemism, endemic plants.

\section{Aetanthus coriaceus Pacz.}

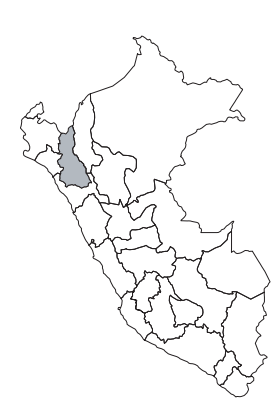

\section{DD}

Publicación: Bot. Jahrb. Syst. 45(4): 437. 1911.

Colección tipo: A. Weberbauer 3938

Herbarios: B; MOL!, USM!

Nombre común: Desconocido.

Registro departamental: CA.

Regiones Ecológicas: MA; 2800-3000 $\mathrm{m}$.

SINANPE: Sin registro.

Herbarios peruanos: MOL (isotipo), USM (isotipo).

Observaciones: Arbusto parásito, conocido aparentemente sólo de la colección original, una planta recolectada en 1904, de una subcuenca del Chicama. Se desconoce el estado actual de sus poblaciones.

\section{Aetanthus ornatus Krause}

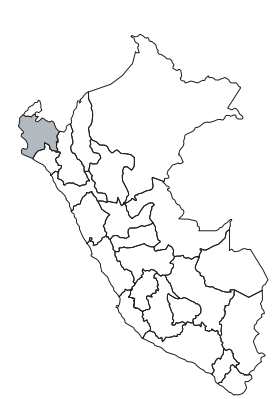

DD

Publicación: Notizbl. Bot. Gart. BerlinDahlem 8: 206. 1922.

Colección tipo: A. Weberbauer 6057 Herbarios: B.

Nombre común: Desconocido.

Registro departamental: PI

Regiones Ecológicas: MA; $2950 \mathrm{~m}$.

SINANPE: Sin registro.

Herbarios peruanos: CPUN (1).

Observaciones: Subarbusto parásito, conocido de unas pocas localidades, con matorrales, sólo del norte del país. Fue descrito de una planta recolectada en 1912, de la cuenca del Huancabamba. Se desconoce el estado actual de sus poblaciones.

\section{Aetanthus paxianus Pacz.}

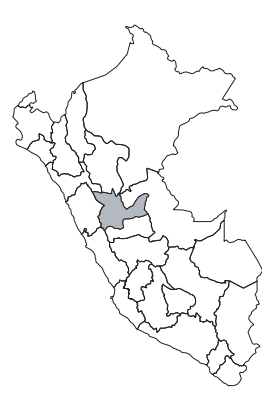

DD

Publicación: Bot. Jahrb. Syst. 45(4): 437438. 1911.

Colección tipo: A. Weberbauer 3390

Herbarios: B; MOL!, USM!.

Nombre común: Desconocido.

Registro departamental: HU.

Regiones Ecológicas: BMHM; 2500$2900 \mathrm{~m}$.

SINANPE: Sin registro.

Herbarios peruanos: MOL (isotipo), USM (isotipo-fragmento).

Observaciones: Arbusto parásito, conocido aparentemente sólo de la cuenca media del Monzón, recolectado originalmente en 1903; esa cuenca alberga varios endemismos, todos ellos registrados a inicios del siglo XX. Se desconoce el estado actual de sus poblaciones.

\section{Oryctanthus ovalifolius (Ruiz \& Pav.) J.F. Macbr.}

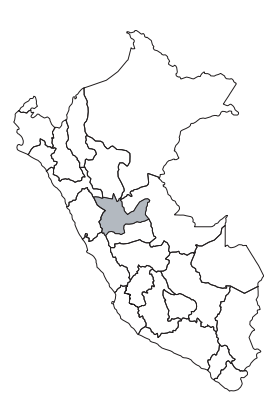

DD

Publicación: Field Mus. Nat. Hist., Bot. Ser. 11(1): 17. 1931.

Colección tipo: H. Ruiz \& J. Pavón s.n.

Herbarios: Ma.

Nombre común: Desconocido.

Registro departamental: HU.

Regiones Ecológicas: Sin datos; altitud desconocida.

SINANPE: Sin registro.

Herbarios peruanos: Ninguno.

Observaciones: Arbusto parásito descrito de una planta recolectada en el siglo XVIII, en la cuenca del Huallaga. Se desconoce el estado actual de sus poblaciones. 


\section{Psittacanthus coccineus Pacz.}

\section{DD}

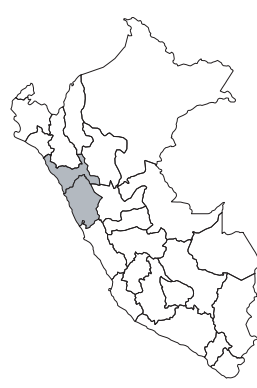

Publicación: Bot. Jahrb. Syst. 45(4): 436437. 1911.

Colección tipo: A. Weberbauer 2643

Herbarios: B; MOL!.

Nombre común: Desconocido.

Registro departamental: AN, LL.

Regiones Ecológicas: MDE, MA; $1400-$ $3400 \mathrm{~m}$.

SINANPE: Sin registro.

Herbarios peruanos: MOL (isotipo).

Observaciones: Arbusto parásito, conocido solamente de dos localidades en la vertiente occidental. Macbride (1937) menciona que la especie crece sobre Salix y Schinus. Desafortunadamente, no hay nuevas recolectas desde 1936. Si bien es de preocupación la modificación y destrucción de los bosques ribereños en la vertiente occidental, se desconoce el estado actual de sus poblaciones.

\section{Psittacanthus peculiaris A.C. Sm.}

\section{VU, B1a}

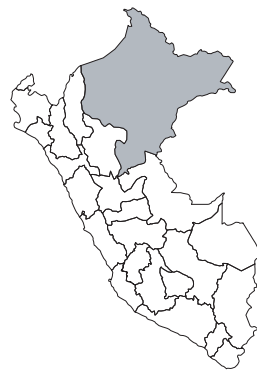

Publicación: Bull. Torrey Bot. Club 58: 90. 1931.

Colección tipo: E.P. Killip \& A.C. Smith 29967

Herbarios: NY.

Nombre común: Desconocido.

Registro departamental: LO.

Regiones Ecológicas: BHA; 120—180 m. SINANPE: RNAM

Herbarios peruanos: AMAZ (5), USM (5).

Observaciones: Arbusto parásito, conocido de bosques no inundables sobre suelos arenosos. Una población se halla en un área protegida de creación reciente, pero que está sujeta a deforestación por expansión urbana.

\section{Psittacanthus subalatus Krause}

\section{DD}

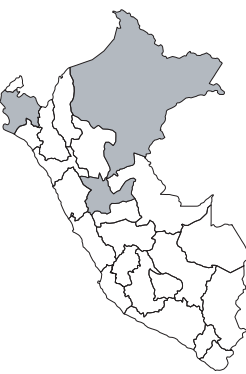

Publicación: Notizbl. Bot. Gart. BerlinDahlem 8: 207. 1922.

Colección tipo: A. Weberbauer 6030

Herbarios: B.

Nombre común: Suelda con suelda (Rimachi 5118)

Registro departamental: HU, LO, PI.

Regiones Ecológicas: BHA; $1400 \mathrm{~m}$.

SINANPE: Sin registro.

Herbarios peruanos: USM (3).

Observaciones: Arbusto parásito conocido de localidades dispersas en el norte y centro del país. El ejemplar tipo fue recolectado en la cuenca del Huancabamba, en 1912. Sin embargo, la mayoría de los ejemplares se conoce de Loreto. Se desconoce el estado actual de sus poblaciones.

\section{Psittacanthus tumbecensis (Killip) J.F. Macbr.}

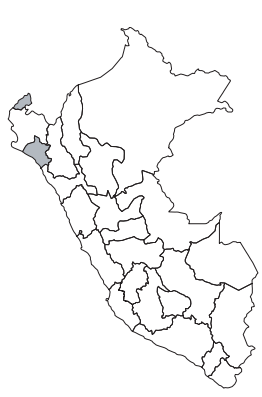

DD

Publicación: Field Mus. Nat. Hist., Bot. Ser. 13(2/2): 408. 1937.

Colección tipo: A. Weberbauer 7668

Herbarios: US.

Nombre común: Desconocido.

Registro departamental: LA, TU.

Regiones Ecológicas: DCT; 500—700 m.

SINANPE: Sin registro.

Herbarios peruanos: Ninguno.

Observaciones: Arbusto parásito, descrito de una planta recolectada en 1927, de una localidad en una quebrada protegida en el matorral xérico de la costa norte. Poco se sabe de la situación de sus poblaciones.

\section{Struthanthus polystachyus (Ruiz \& Pav.) G. Don}

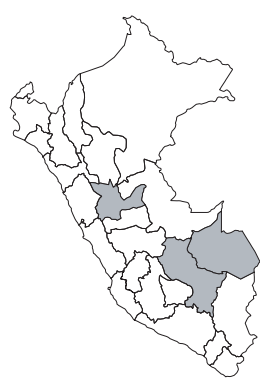

Publicación: Gen. Hist. 3: 410. 1834.

Colección tipo: E.F. Poeppig 1337

Herbarios: B.

Nombre común: Desconocido.

Registro departamental: CU, HU, MD.

Regiones Ecológicas: BHA; 210—400 m.

SINANPE: PNM

Herbarios peruanos: USM (4).

Observaciones: Arbusto parásito, considerado por Brako \& Zarucchi (1993) como un endemismo; sin embargo, no ha sido posible evaluarlo, ni asignarle una categoría.

\section{Struthanthus tenuis Patcz.}

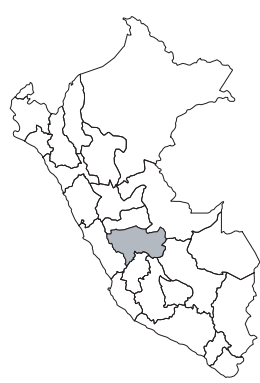

Publicación: Bot. Jahrb. Syst. 45(4): 438. 1911.

Colección tipo: A. Weberbauer 1948

Herbarios: B; MOL!

Nombre común: Desconocido.

Registro departamental: JU.

Regiones Ecológicas: Sin datos; altitud desconocida.

SINANPE: Sin registro.

Herbarios peruanos: MOL (isotipo).

Observaciones: Este taxón fue considerado por Brako \& Zarucchi (1993) como un endemismo; sin embargo, no ha sido posible evaluarlo, ni asignarle una categoría.

\section{Tristerix chodatianus (Patcz.) Kuijt}

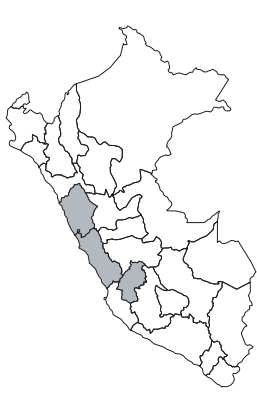

\section{DD}

Publicación: Syst. Bot. Monogr. 19: 25. 1988. Colección tipo: A. Weberbauer 2934

Herbarios: G; MOL!

Nombre común: Desconocido.

Registro departamental: AN, HV, LI.

Regiones Ecológicas: PSH, PAR; 3800— $4300 \mathrm{~m}$.

SINANPE: PNH

Herbarios peruanos: CPUN (5), MOL (isotipo).

Observaciones: Arbusto parásito conocido de varias poblaciones dispersas, en las cuencas del Rímac, Santa y Mantaro. Se desconoce el estado actual de sus poblaciones, pero podrían estar amenazadas por destrucción de los fragmentos de bosque. 


\section{Tristerix peruvianus (Patcz.) Kuijt}

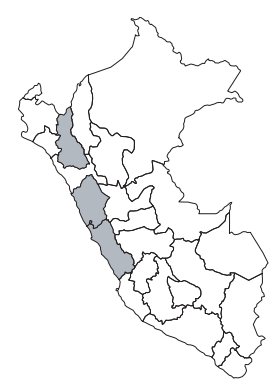

Publicación: Syst. Bot. Monogr. 19: 40. 1988.

Colección tipo: P.C. Hutchison \& J.K. Wright 7072

Herbarios: F, NY, UC, US; USM!

Nombre común: Desconocido.

Registro departamental: AN, CA, LI.

Regiones Ecológicas: MA; $2900 \mathrm{~m}$

SINANPE: Sin registro.

Herbarios peruanos: USM (isotipo+3).

Observaciones: Este taxón fue considerado por Brako \& Zarucchi (1993) como un endemismo; sin embargo, no ha sido posible evaluarlo, ni asignarle una categoría.

\section{Tristerix peytonii Kuijt}

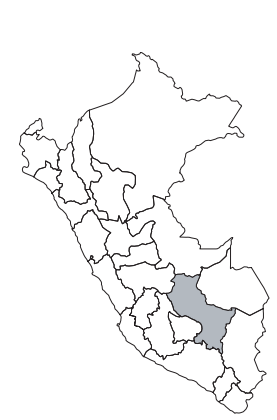

DD

Publicación: Syst. Bot. Monogr. 19: 2829, f. 9, 19. 1988.

Colección tipo: B. Peyton \& T. Peyton 770

Herbarios: LEA, MO.

Nombre común: Desconocido.

Registro departamental: CU.

Regiones Ecológicas: BPM; 2700—3715

m.

SINANPE: SHMP

Herbarios peruanos: USM (1).

Observaciones: Arbusto parásito, conocido solamente de unas pocas colecciones, todas provenientes de Cusco. La mayoría de las recolectas han sido realizadas en la cuenca del Urubamba. Se desconoce el estado actual de sus poblaciones

\section{Tristerix pubescens Kuijt}

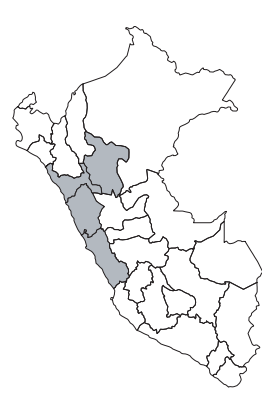

\section{NT}

Publicación: Syst. Bot. Monogr. 19: 3638, f. 8, 12. 1988.

Colección tipo: J. Mostacero L. et al. 597 Herbarios: F, LEA, MO, UC, US; HUT.

Nombre común: Desconocido.

Registro departamental: AN, LL, LI, SM. Regiones Ecológicas: PSH, PAR; 3700$4200 \mathrm{~m}$.

SINANPE: PNH, PNRA

Herbarios peruanos: HUT (isotipo citado), USM (12).

Observaciones: Arbusto parásito, conocido de varias localidades en el centro del país. Esta especie es conocida de bosques de Poblepis, al cual parasita, en las Cordilleras Blanca, Huayhuash y la de Lima. Parasita también arbustos como Berberis. 